\title{
Quantification and contribution of nitrogen inputs in the soil on groundwater contamination by nitrates: Valley of High-Cheliff (North Algerian)
}

\author{
Amina Richa', * , Abdelkader Douaoui', Naima Bettahar² \\ 'Laboratory Agricultural Production and Sustainable Exploitation of Natural Resource, University of Khemis Miliana, Khemis \\ Miliana, Algeria \\ ${ }^{2}$ Laboratory Water \& Environment, University Hassiba Ben Bouali, Chlef, Algeria. BP 151-02000 - Chlef, Algeria.
}

*Corresponding author e-mail : amricha@yahoo.fr

Received : 17.12.2013

Accepted: 14.04.1014

\section{Abstract}

Nitrogen $\left(\mathrm{N}_{2}\right)$ is an essential nutrient for plants. However, when the application of nitrogen exceeds the needs of the plant and the denitrification capacity, nitrogen can migrate to groundwater, usually in the form of nitrates. The transfer of nitrates in soil results from a large number of interdependent factors: climatic, agrological, and agronomic. The Conditions of interaction of these factors can lead to situations more or less favorable to leaching of nitrates. Thus, according to some studies in agronomy, high levels of nitrate pollution observed result from an increase in the mineralization capacity of soils under the cumulative effect of intensive farming practices. Many European countries and some U.S. states are already based on the nitrate test for establishing the optimum nitrogen doses. In agricultural areas, the use of large amounts of mineral fertilizers and the increased volume of animal waste as a result of development of breeding cause nitrogen excess surplus capacity utilization by the vegetation, it is driven into groundwater and causes an increase in nitrate concentrations. With a total annual volume of agricultural production of around 1.5 million tons, agriculture is certainly the pole par excellence of the Hight-Cheliff. The main crops are arboriculture and gardening. Potatoes covered nearly half (48\%) of the total volume of agricultural production, it is a major consumer of Nitrogen fertilizers. For the purpose of estimate the amount of leachable nitrogen, nitrogen balance was drawn up, see all the inputs and outputs of nitrogen were almost estimated. This study associate groundwater nitrate pollution with agricultural activity in the high-Cheliff intensive farming regions in Algeria. The spatial probability distribution of nitrate contents, based on nonlinear methods of indicatory kriging, shows the spatial evolution of nitrate through a map established for the year 2011 during high waters. The obtained results show that the areas exceeding nitrate concentrations of 50ppm, occupy more than $80 \%$ of the aquifer area, it appears, from this map, the most affected areas are those for with the level of intensification of nitrogen fertilization is strongest specially in the zone of potatoes crops. These results are coherent with the experimental data, which show an average nitrate concentration value of $75 \mathrm{ppm}$, significantly higher than the WHO'S maximum contaminant level. In this study the estimate of the total nitrogen inputs to soils of the valley was $247 \mathrm{Kg} \cdot \mathrm{ha}^{-1}$ for this year and compared it with the results of Computer models such as PILOTEN used to analyze alternative management practices together with soil, plant, and climate characteristics to determine nitrogen leached under the potatoes crops ( hot spot areas). The result show that 60\% of nitrogen input is leaching under potato crops which coherent with the spatial evolution of nitrate.

Keywords: Groundwater, Nitrate Pollution, Fertilizers, indicatory kriging, PILOTEN, Algeria.

\section{INTRODUCTION}

Nitrate pollution of groundwater is depleting rapidly with the ever-increasing massive industrialization, urbanization, and the agricultural expansion with its associated activities that pose high pressure on groundwater resources [1] it

has been highlighted by several studies on different aquifers in Algeria [26] [22]. It is often associated with intensive farming [9]. In the plain of High-Cheliff located in the North Algerian or main activity revolves around agriculture, the risk 
of nitrate pollution threatens water resources. With a total annual volume of agricultural production around 1.5 million ton, agriculture is certainly the destination by excellence in the region, Potato, covered nearly half (48\%) of the total agricultural production of High-Cheliff and provides more than $40 \%$ of the national production of potato, the latter being a major consumer of nitrogen fertilizer types. This work helps to visualize the extent of the pollution and to determine its origin and the main mechanisms that govern it.

\section{MATERIALS AND METHODS}

\section{Study Area}

The study area located north-west of Algeria (Fig. 1).It is bordered to the south by the foothills of the chain Ouarsenis and north by the mountains of Zaccar, east and west. It occupies an area of 370 $\mathrm{km}^{2}$ in the basin of the High-Cheliff. The plain is between the following coordinates:

$36^{\circ} 12^{\prime}$ 'and $36^{\circ} 17^{\prime}$ ' north latitude and $12^{\circ} 2$ 'and $2^{\circ} 17^{\prime}$ ' east longitude.

The region exhibits a Mediterranean semi-arid climate with long hot summer and short warm winter. The considerable difference between the maximum recorded temperature in July $\left(46^{\circ} \mathrm{C}\right)$ and minimum in the month of January $\left(0^{\circ} \mathrm{C}\right)$ reflects a marked continentality despite its proximity to the sea because the massive of Zaccar barrier isolating the High-Cheliff to the influence of the Mediterranean. The water balance established in 2011 by the Thornthwaite method on data from the rainfall station-Khemis Miliana (station of Harraza) indicates a relatively high evapotranspiration and water deficit with 923.38 $\mathrm{mm}$ and $562.58 \mathrm{~mm}$ respectively, in parallel with deduced operating surplus water is only $5 \%$ of the total rainfall (203 mm).

\section{Hydrogeological Context}

Quaternary forming the embankment of the valley include sand, gravel or clay and sandstone that vary from a few meters to over $150 \mathrm{~m}$. It is exploited with an average annual volume of approximately $19.4 \mathrm{hm}^{3}$ [2], of which $32 \%$ is for drinking water, irrigation $61 \%$ and $7 \%$ industrial uses [34] [33].

Lithologic descriptions [4] indicate that below the zone of soil, large sections of clay materials covering the same ancient alluvial deposits of the corresponding plain of silty clayey deposit of recent Quaternary. These layers are located in the north and south of the valley with average thicknesses of 8 to $10 \mathrm{~m}$. To the north and west is a thick clay profile that offers low permeability does not allow sufficient recharging the aquifer horizon. Instead, on the edges of the valley, more permeable formations are the unsaturated zone.

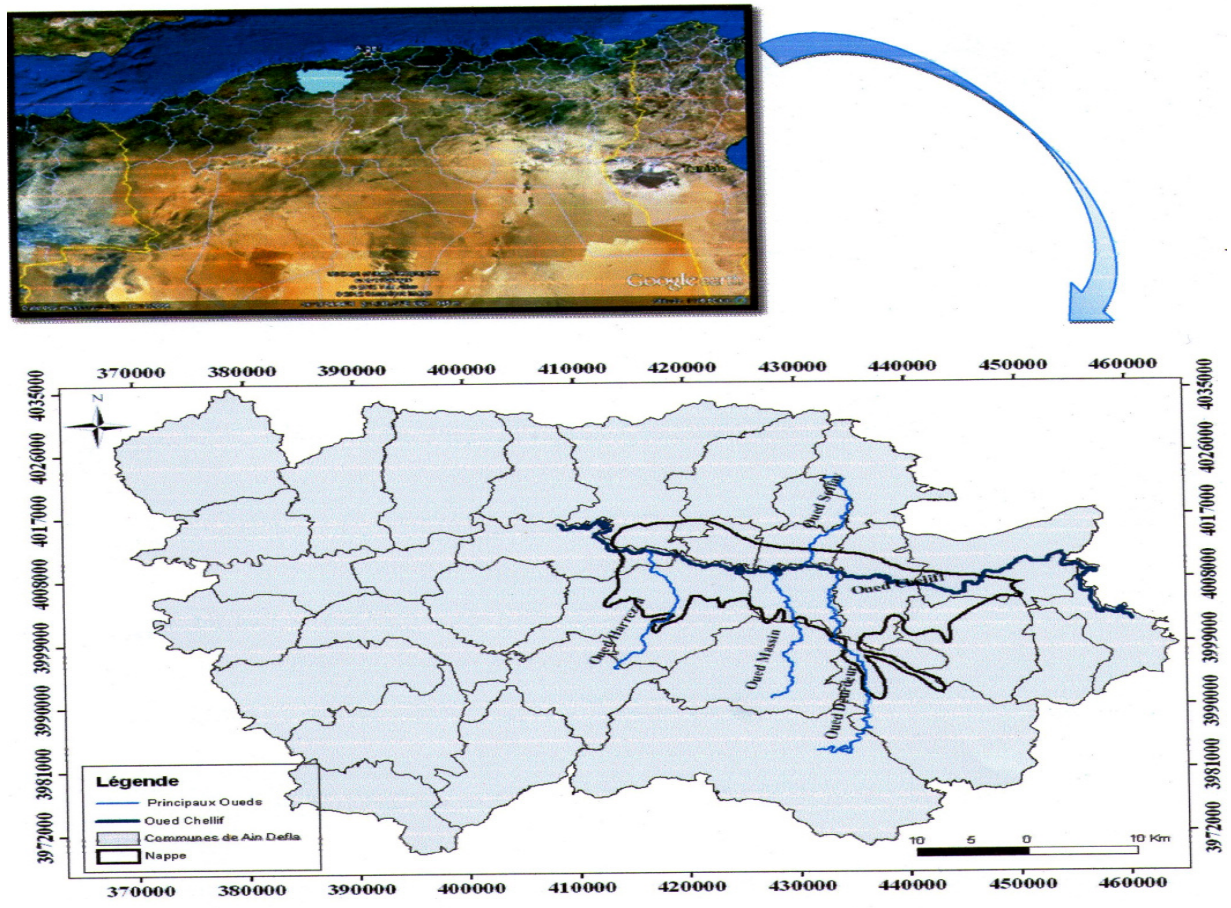

Figure 1. Map of the study area 
The monitoring network with 15 wells and 34 wells and four piezometers enable study the chemical changes in the water mass and groundwater levels.

The piezometric map established for the month of May 2011 shows closed curves in the center of the plain and opens to the edges (fig.2). This indicates power from the borders to towards the plain. Perpendicular to the axis of the valley piezometric lines converges toward the center of the plain before taking a direction parallel to the EO during the Cheliff wadi. Depressions are observed in the east of the plain due to the effect of intensive pumping for agricultural purposes.

In addition to the meteoric water, the water gets a significant power north from the Jurassic limestone manifested by a strong gradient $(0.9 \%)$ in a northeasterly direction. Receives another lower supply from the Cheliff river and tributaries (Deurdeur, Souffay, Boutane ......), with a gradient $(0.7 \%)$.

\section{Soil Context}

The soil studies related to the Valley Cheliff which is an alluvial plain with high agricultural potential are numerous [12] [15], soils often have a structure in average to poor stability [16] [22].The soils of the plain are formed in Quaternary alluvium [12] [15]. These soils is in majority poorly differentiated, more or less calcareous variable texture, sometimes with locally hydromorphic with the presence of vertic soils.

There are two main groups:

- Soils piedmont only observed on the edges of the valley, is balanced texture (40\% sand, 35\% silt, 25\% clay), well structured and has therefore a very good permeability. The high permeability of these soils results in the transport of water infiltration into the deeper layers is very fast. The dwelling time of water in the surface layers is very short, so that nitrates are leached faster than the speed of biological processes (microbial organization, absorption by a covered).

- The soils of the plain (alluvial) are generally locally variable clay texture. Heavy soils $(\geq 40 \%$ clay on average) are important in the most recent alluvial formations such as plain Djellida and the left bank of the plain of El Khemis they may show signs of water logging and salinity (conductivity between 2 and 72 $\mathrm{dS} . \mathrm{m}^{-1}$ ) related to a local deficient internal drainage, causing the decline in already low permeability.

Table 1. Soil characteristics (surface horizon: 0-30 cm)

\begin{tabular}{cccccccc}
\hline & $\mathrm{pH}$ & $\mathrm{C} . \mathrm{E}\left(\mathrm{dS} . \mathrm{m}^{-1}\right)$ & $\mathrm{CaCO}_{3} \%$ & M.O $\%$ & Clay $\%$ & Limon \% & Sand \% \\
\hline $\begin{array}{c}\text { Horizon 0- } \\
\text { 30cm }\end{array}$ & 7,7 & 1,4 & 3,17 & 2,3 & 32 & 43 & 25 \\
\hline
\end{tabular}

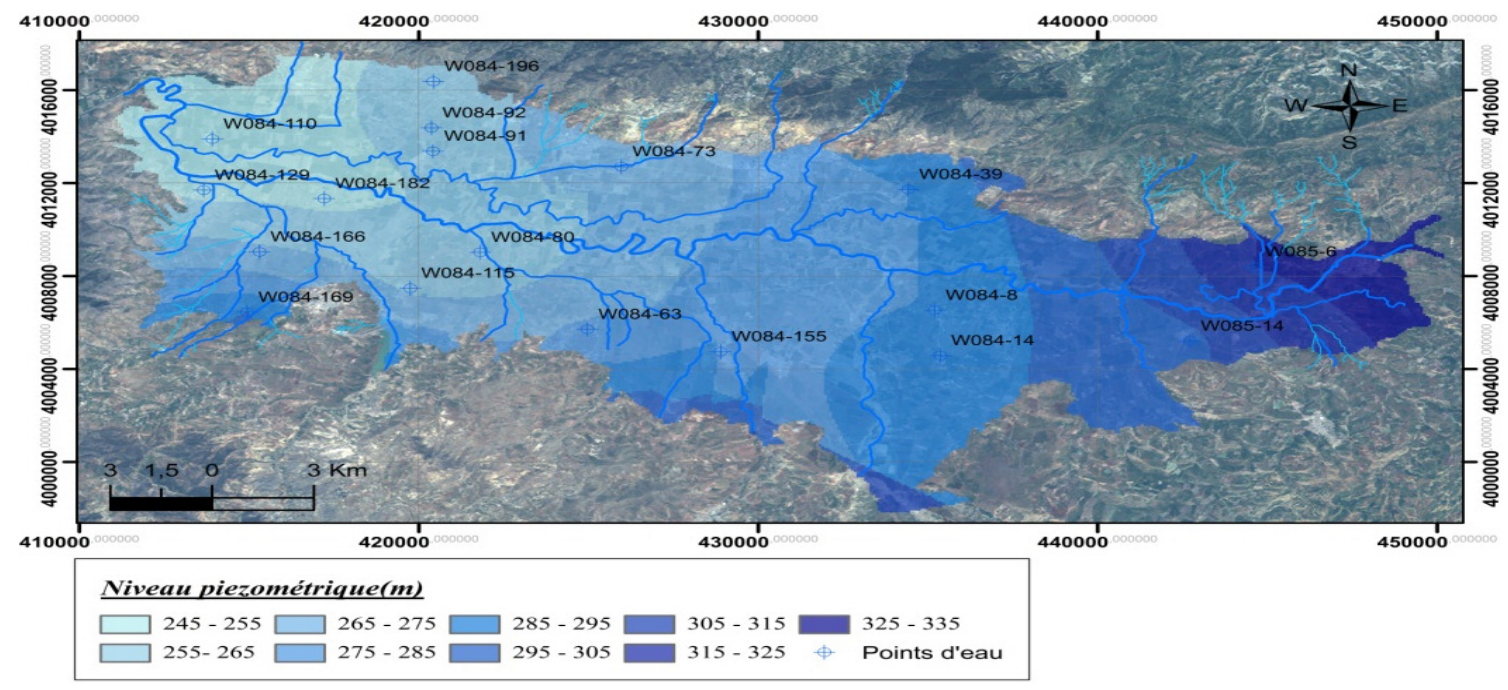

Figure 2. Hydrogeological context of the high-Cheliff 


\section{Land Occupation}

The information collected from the direction of the agricultural department of Ain Defla report for the areas of agricultural land of which 18\% are actually irrigated, the garden farming is the most important perimeter speculation, concentrated throughout the valley and especially in the west side, it is irrigated from wells and drillings (boreholes) in the area and releases from dams Ghrib, Deurdeur and Harraza. The annual average concentrations of nitrates in waters of the dams are low (<20 mg / I) [5] and can act as diluents.Covering a total area of 5636ha, garden farming occupies the first position of importance and is located mainly near the edges of the valley (the Aribs, Djendel Sidi lakhder, Djelida), their irrigation is provided by individual wells.

\section{Sampling and Analytical Methods}

A total of 51 groundwater samples irregularly distributed covering several geomorphologic, soil, and land cover units in the area were collected from shallow (mostly $<120 \mathrm{~m}$ deep) wells during field campaigns carried out in May 2011 . A piezometric campaign and chemical analysis was carried out after application of large amounts of nitrogen fertilizer, especially fertilizers background on garden crops. Water depths in the wells ranged from 4 to $40 \mathrm{~m}$ with an average oscillating around $18 \mathrm{~m}$. Samples of water filtered at 0.45 microns using syringe filters (Sartorius) are taken in stoppered plastic (polyethylene), previously rinsed with filtered water sample, and immediately stored to keep temperature below at $4^{\circ} \mathrm{C}$ until arrival at the laboratory.

In the laboratory, they are placed in the refrigerator and analyzed within 24 hours of collection. The physico-chemical parameters (T, pH, conductivity) were in situ measured using a multiparameter WTW Universal Conductivity Meter Multi-Line P4 set and probes. The analysis of chemical elements was performed by the following methods (Rodier, 1996): the calcium, hardness (TH), magnesium, chloride and bicarbonate by titration, sodium and potassium were determined by the spectrophotometer flame emission (brand JENWAY PFPZ) on the wave lengths of 589 and 766.5 nm.n. Sulphates and nitrates were determined by a spectrophotometer HACH DR/4000 brand model 48000 ) on the wavelengths 420 and $415 \mathrm{~nm}$, the estimated absolute error of the various chemical and physico-chemical parameters are identified in Table
2. For different analyzes the ionic balance is less than $5 \%$. The ordinary and indicator kriging with semivarogram modeling implemented in the geostatistical analyst of the ArcGIS9.3 package was then used to produce spatial maps of the measured and estimated spatial evolution of nitrate in groundwater. For modeling the effects of potato crop agricultural practices on nitrate leaching, the PILOTEN model was selected.

\section{Spatial Prediction Of Nitrate /Geostatistical Modeling)}

The indicator kriging can map the probabilities of different threshold levels of nitrate retained and the average probability of nitrates by calculating their mathematical expectation. The indicator kriging is a nonparametric method based on a prior transformation of the variable studied indicator taking the value 0 and 1 according to the thresholds chosen variable [1 1] [18]. Spatial analysis of this type of kriging is not done on the variable itself but on the transformed this variable by binary coding called indicator function. The threshold values (threshold values) depend, in our case, the limits of nuisance or toxicity (drinking water standards).

The calculation of the indicator variogram functions given threshold determines the spatial structure.

$$
\gamma^{*}(h, c)=\frac{1}{2 N}(h) \sum_{i=1}^{N(h)}\left[I\left(x_{i}, c\right)-I\left(x_{i}+h \pm \Delta h, c\right]^{2}\right.
$$

where: $N(h)$ is the number of pairs of remote observations of $h \pm \Delta h$

Ordinary Kriging at a point $(\mathrm{x} 0)$ of I $(\mathrm{xi}, \mathrm{c})$ is done according to the equation:

$$
I *\left(x_{0}, c\right)=\sum_{i=1}^{n} \lambda_{i} I\left(x_{i}, c\right)
$$

$\mathrm{n}$ :the number of data points included in the estimate

$\lambda_{j}$ :the weight assigned to the experimental points

The difference between the estimates of indicator functions for two consecutive threshold values used to calculate the corresponding probability at any point:

Probability $(X=c)=$ Probability $\left(X \geq Z_{c}\right)$ - Probability $\left(X \geq Z_{c+1}\right)$ 
$Z_{c}$ and $Z_{c+1}$ are the two are Followed threshold values

The mathematical expectation is calculated according to the different probabilities used:

$$
E(Z)=Z_{c}+2 Z_{c+1}+3 Z_{c+2}+\ldots \ldots
$$

\section{Modelling}

PILOTEN model was selected for simulating the effects of potato crop agricultural practices on nitrate leaching, in the high-Cheliff. PILOTEN is a cultural model developed by Irstea which principles are specified in particular in Articles of Mailhol et al. (1997) and Khaledian et al. (2009).

It requires climate given at a daily weather: Rain, reference evapotranspiration (ETO), global radiation and mean temperature. It also requires information on the plant (planting date, root growth, physiological status, conversion efficiency) and ground (initial water reserve, volumetric water content at field capacity and wilting point) [25] .

It consists of two main modules: "Soil" module, which models the water transfers in the soil using three compartments (or reservoirs): a surface reservoir, which manages the exchange of the atmosphere with water median reservoir, which evolves with rooting and a deep reservoir, located below the root front and which is limited by the maximum rooting; "plant" module, which simulates the evolution of the LAl, Leaf Area Index according to water conditions and temperatures corresponding to different stages of plant development [30] [31]. Soil evaporation and crop transpiration rates take into consideration the evolution of leaf area index (LAl) and the soil water content.

Associated with climate data (rainfall, average temperature, evapotranspiration, global radiation) the period over which the simulation is done, the combination of two modules provides for a culture and soil characteristics data, an estimate of yield and water consumption required to achieve this performance [32]. La conduite de l'irrigation (dates et quantités d'eau apportées) peut être défin (inputs other than irrigation are assumed to be non limiting). PILOTEN performs a complete nitrogen balance in a simulation period. The software also evaluates the $\mathrm{N}$ draining [21] and $\mathrm{N}$ leaching. It is a well-known code that has been used to estimate the leaching of nitrogen.

\section{RESULTS AND DISCUSSION}

\section{Nitrate Mapping}

Two threshold values were used: the first corresponds to greater than $50 \mathrm{mg} / \mathrm{l}$ which is the maximum limit set by the WHO levels: the second value equal to $80 \mathrm{mg} / \mathrm{l}$ is chosen taking into account the distribution of data and a limit beyond which the water consumption is very dangerous.

The average variogram (omnidirectional) calculated for the mathematical expectation of nitrate shows a good spatial structure with a range equal to $11900 \mathrm{~m}$.

The latter expresses that good spatial continuity also shows a pattern in the spatial variability of nitrates in view of the high ratio between the address which is equal to $0.26(\mathrm{mg} / 1)^{2}$ and the nugget effect equal to 0.04 (mg / I) (fig.6).
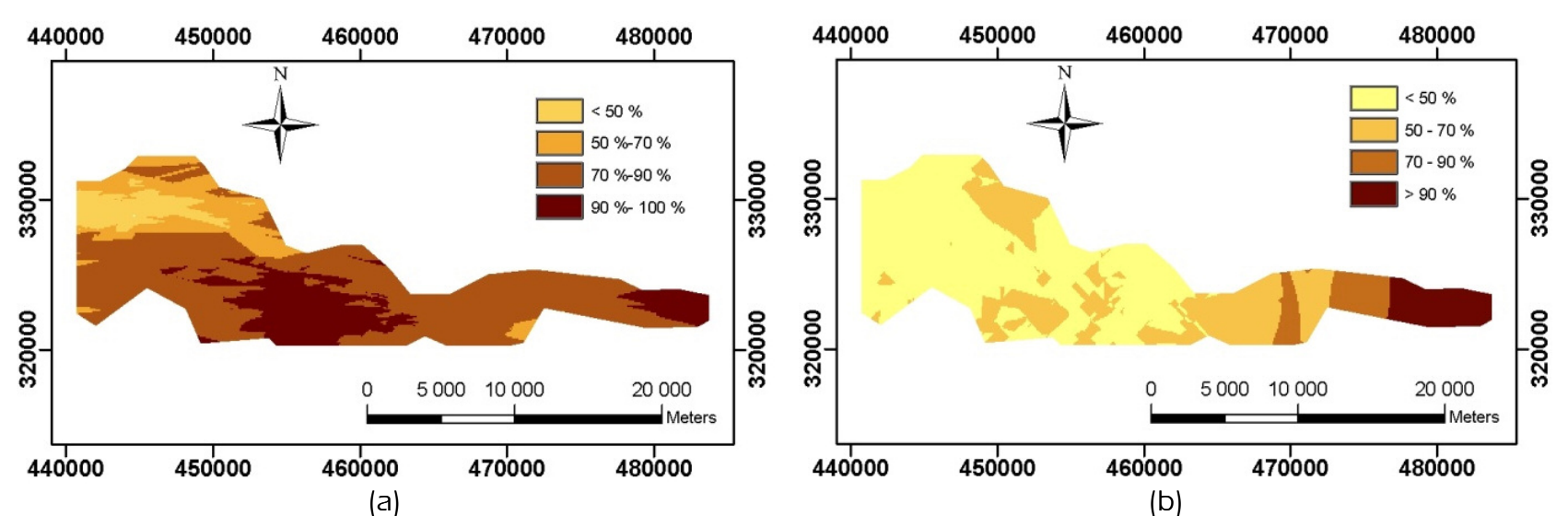

(b)

Figure 3. Maps of the probabilities estimated by indicator kriging thresholds $50 \mathrm{mg} /$ / (a) and $80 \mathrm{mg} /$ / (b) 
The map established by Indicator Kriging (IK) method Map of the mathematical expectation of nitrate is established to map the spatial distribution of nitrate within the parameters of the variogram (Fig.6). It appears from this map that the most contaminated surfaces $\left(\mathrm{NO}_{3}>65 \mathrm{mg} / \mathrm{l}\right)$ are those for which the level of intensification of nitrogen fertilization (zone of garden farming, potato in particular benefitting from a phenomenal nitrogen fertilization). [9].

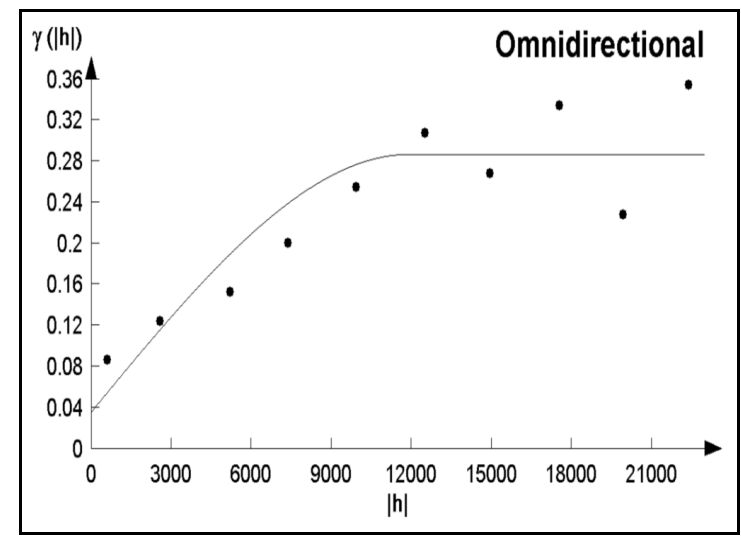

With Natural contributions=Atmospheric nitrogen contributions+Contributions by mineralization

Non natural contributions $=\mathrm{N}$-fertilizers + water of irrigation + breeding + municipal wastewater

$A=$ Absorption by the plants, $V=$ volatilization, $D=$ denitrification and $L=$ Leaching.

It is nitrogenous balance method proposed by the COMIFER (1996) and the CORPEN (1988),

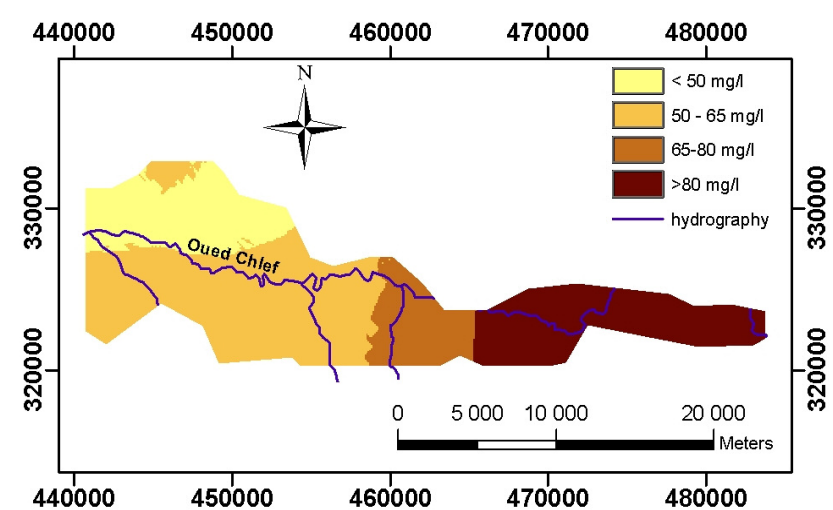

Figure 4. Variogram and Map of nitrate concentrations estimated by ordinary kriging

It is east of the plain where the old alluvial soils and non-clayey foothills are characterized by the highest permeabilities [42]. The sensitivity of the soil to nitrate leaching is therefore very high. In these same areas, the exploitations of the breeding are more intensive. As to the southwest extension, it contains a high nitrate levels $\left(\mathrm{NO}_{3}\right.$ $>50 \mathrm{mg} / \mathrm{l}$ ) despite the very fine texture of the soil, this is due to the accumulation of pollution in the direction water flow from the upstream to the downstream hydraulic. With the exception of a zone located in the extreme north, the weak values surfaces are located in the northwest of the plain and do not exceed $50 \mathrm{mg} / \mathrm{I}$. In this area, fine texture of the soil reduces significantly the spread of nitrates in depth view of the low permeability [13].

\section{Quantification Of Total Nitrogen Inputs In} The Study Area

The estimate of the total nitrogen input can be given by the following equation:

$$
\sum \text { ENTRIES }=\sum \text { EXITS }
$$

Natural Contributions+non natural contributions $=\mathrm{A}+\mathrm{V}+\mathrm{D}+\mathrm{L}$ permits the nitrogenous excess calculation. In this work we have interesting for calculate or quantification of the nitrogen input from the non natural contribution during the year 2011 they are valued to $5633 \mathrm{~T}^{\text {.year }}{ }^{-1}$ brought on the soils of the plain High-Cheliff during this year. Nitrogen brought by agriculture (fertilizers and irrigation) $62 \%$ of the total nitrogen applied to soils of the region. $90 \%$ of the latter is attributed to nitrogen fertilizer intensively used in garden farming, potatoes in particular. Extrapolated to the total irrigated area, this contribution (related to fertilizers) is estimated at $247 \mathrm{~kg} \cdot \mathrm{ha}^{-1}$ for this year.

\section{Contribution from fertilizers}

A field investigation from 350 agricultural exploitations has allowed us to develop a calendar of cultural practices (dates, fertilization) and estimate, therefore, nitrogen inputs for each type of land use. The industrial chemical fertilizers, especially, 15.15.15 NPK is predominant in almost all of the exploitations with annual average doses of $2000 \mathrm{~kg}$. ha-1 for potato, used as background fertilizer. Other fertilizers such as urea (46\%) and sulfate of ammonium used as cover fertilizer. 
Table 2. Results of the investigation into the agricultural practices in the High-Cheliff

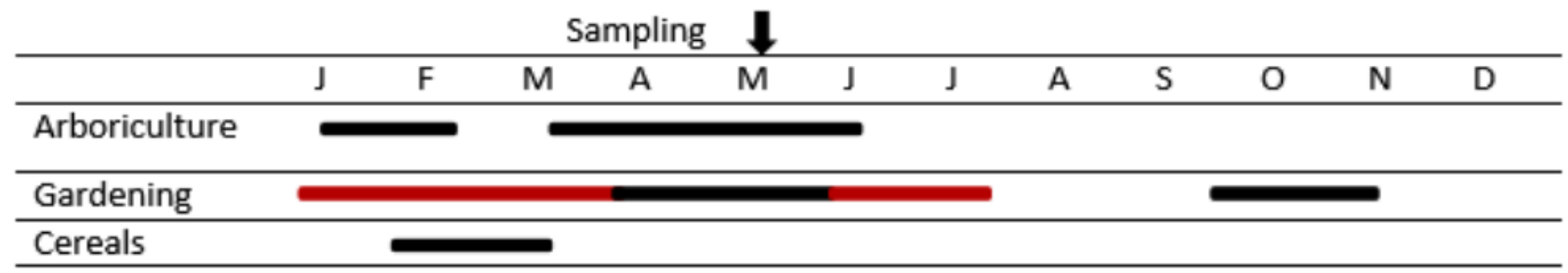

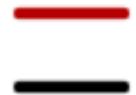

\section{Background fertilizer spreader (NPK 15.15.15) \\ Cover fertilizer spreader (Urea46\%, 21\% sulfate of ammonium)}

The amount of nitrogen obtained for each crop type is deducted of the product of the dose of fertilizer that it receives by the corresponding area application.

\section{Contribution from the water of irrigation}

Garden farming and cereals surfaces are irrigated from groundwater of which nitrate concentrations, for the majority, exceed the potability standard (50 $\left.\mathrm{mg} \cdot \mathrm{L}^{-1}\right)$ [8]. Referring to the potability standard (50 $\left.\mathrm{mg}^{\mathrm{L}} \mathrm{L}^{-1}\right)$, we can estimate the amount of nitrogen in this water using the formula below [32]; [10]

$$
\mathrm{Xn}=\frac{\left[\mathrm{NO}_{3}-\right] \times \text { Qirrig }}{4.43 \times 10^{2}}
$$

$X_{N}$ is the annual amount of nitrogen applied by irrigation water $\left(\mathrm{KgN} \cdot \mathrm{ha}^{-1} \cdot \mathrm{an}^{-1}\right),\left[\mathrm{NO}^{-3}\right]$ is the concentration of nitrate in well water $\left(\mathrm{mg} \mathrm{L}^{-1}\right)$ Qirrig and the annual amount of irrigation water $\left(\mathrm{mm} \mathrm{an}^{-1}\right)$. The 4.43 figure is the ratio of molar masses $\mathrm{NO}_{3} \cdot \mathrm{N}^{-1}$. The total quantity of nitrogen brought by the water of irrigation for the year 2011 was 344.58t/year (Fig.7) which represents only $10 \%$ of the one produced by the nitrogen fertilizers(3139.65t/year).

\section{Contribution from breeding}

The calculation of yearly total quantities of organic nitrogen generated by the set of each animal category for the year 2011 is based on the values of nitrogen produced annually per head for each species proposed by the (CORPEN 1988 , 1999 and 2001). The results that we obtained show that the majority of this organic nitrogen is produced by cows (1515.7 t/ year).

\section{Domestic and industrial inputs}

The average rate of connection of the population to wastewater systems is approximately $98.57 \%$ to the municipalities of El Khemis and Sidi Lakhder is lowered to $70 \%$ in areas (Arib, Ain Sultan) or autonomous sanitation (individual and collective septic tanks) and is highlighted. The estimate of the yearly total quantities of organic nitrogen produced by domestic sewage is based on the nitrogen content of the volume of domestic wastewater populations not connected to the sewage network. The quantity of nitrogen produced so calculated (344.58 t / year) is only about $23 \%$ of that generated by breeding.The nitrogen produced by nitrogen fertilizers is estimated about $56 \%$ of the total nitrogen input added to the soil of the plain High-Cheliff for 2011. The contribution from breeding and domestic wastewater assessed for 2011 represents about $38 \%$ of the total nitrogen (5633.13 t) brought on the soils of the valley High-Cheliff during this year.The dumps, often seen on permeable soils, can also convey important quantities of nitrates in depth difficult to quantify at this stage of study.

\section{Modelling Results of $\mathbf{N}$ Leaching Under Potato Crops}

Simulated amounts of water infiltrated and $\mathrm{N}$ leached past $0.9 \mathrm{~m}$ depth for each potato crop period are shown in graphs As encountered by other authors [17], days when $\mathrm{N}$ leaching occurs correspond to days with heavy rains or irrigation (Tab.2) 


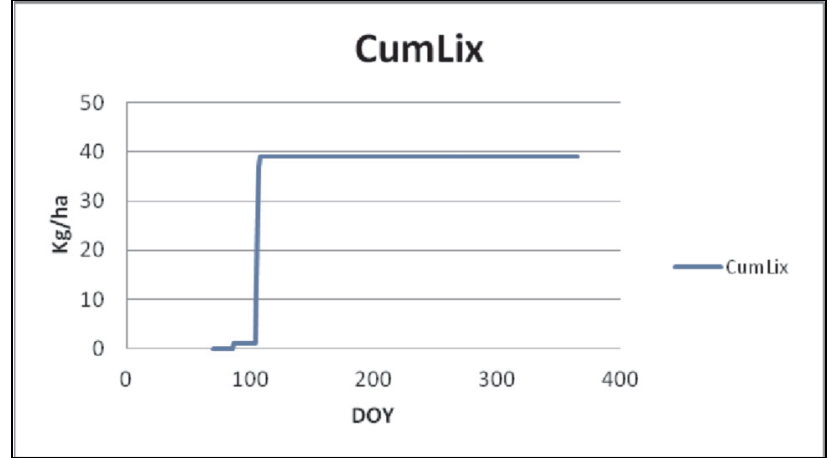

a) Cumulative nitrogen leached

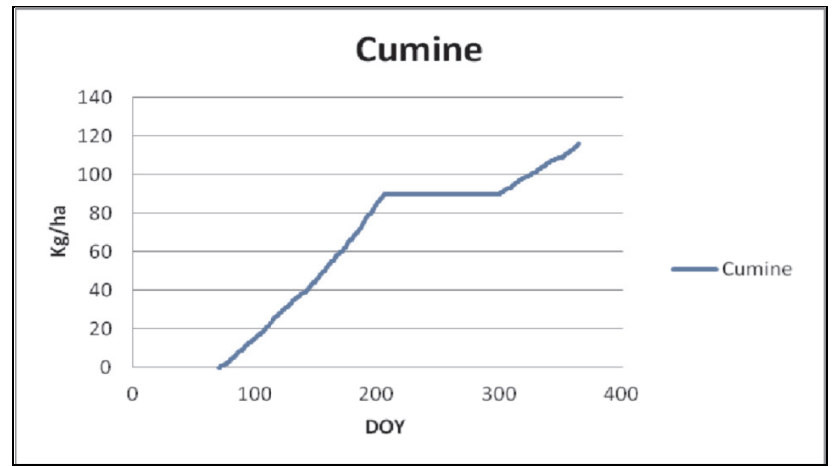

c) Cumulative nitrogen mineralized

Figure 5. Nitrogen balance for potato crops for 2011

With regards to nitrate leaching, the main difference between rainfall and the application of irrigation water is the concentration of nitrate it holds. The average nitrate concentration in rainwater over the whole studied period was in the order of $6 \mathrm{mg} \mathrm{l}^{-1}$, whilst in irrigation water pumped from the Mio-Plio-quaternary aquifer the nitrate concentration oscillated between 80 and 300

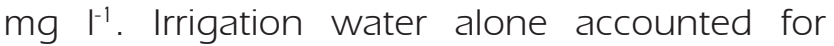
an input of 344 T/year for the 2011 ,

The period of leaching $N$ is as well as timing of fertiliser applications and irrigation groundwater. Over this period there was a $134 \mathrm{~mm}$ increase in drained water, which transported $143 \mathrm{~kg} \mathrm{~N} \mathrm{ha}^{-1}$. The total $\mathrm{N}$ leached for the 2011 crops was $148 \mathrm{~kg} \mathrm{~N} \mathrm{ha-1}$, this implies that the intensification of fertilizer and irrigation frequent applications played an important role in the total $\mathrm{N}$ leached increasing .

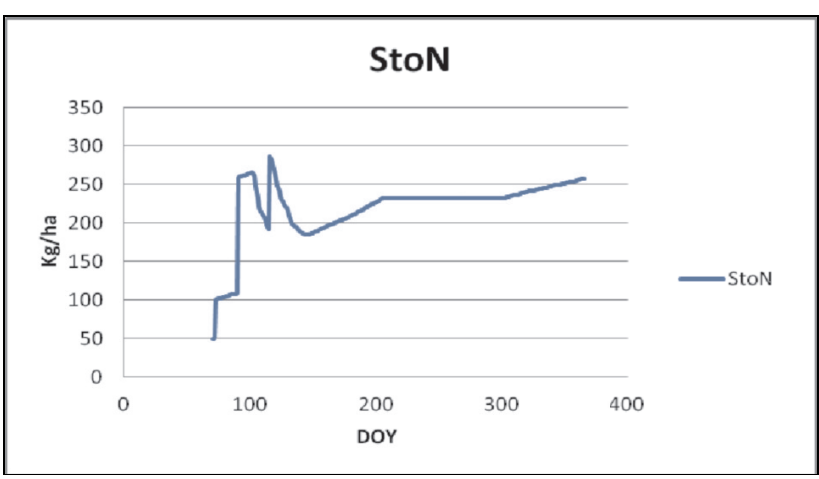

b) cumulative nitrogen stock in the soil

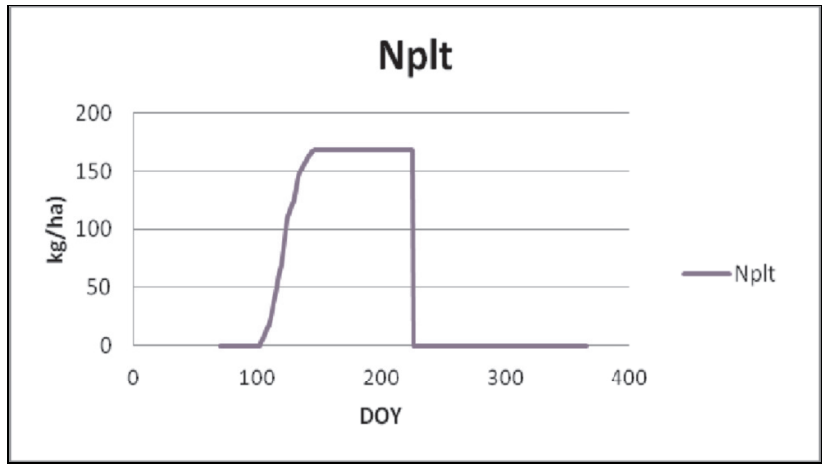

d) cumulative nitrogen absorbed by the plant

The nitrogen produced by fertilizers is estimated about $56 \%$ (154 $\mathrm{kg} \mathrm{N} \mathrm{ha}^{-1}$ ) of the total nitrogen input added to the soil of the plain HighCheliff for 2011, the model of simulation shown that $95 \%$ of $\mathrm{N}$ lixiviation was from the potatoes crops the same zone located to the map of nitrate established by ordinary kriging.

\section{CONCLUSIONS}

The spatial relationship between $\mathrm{NO}_{3}$ concentrations in well waters and the $\mathrm{N}$ leaching under potato crops were studied in the HighCheliff Plain. Nitrate pollution in aquifers of the High-Cheliff in semi-arid climate seem. Indeed, important quantities of nitrogen (5500 T), brought annually to the soils of High-Cheliff valley by different practices (agriculture, breeding.....), don't reach the aquifer because of the climate and the soil characteristics. It can be concluded that the indicator kriging method, correctly reflects the potential risk of nitrate pollution exceeding the

Table 3. Simulation results of nitrogen balance of potatoe crops

\begin{tabular}{cccccc}
\hline $\begin{array}{c}\text { Total rain } \\
\mathrm{mm}\end{array}$ & $\begin{array}{c}\text { Evaporation soil } \\
\mathrm{mm}\end{array}$ & Drainage $\mathrm{mm}$ & $\mathrm{N}$ lessives $\mathrm{kg} / \mathrm{ha}$ & $\begin{array}{c}\text { Mineralization } \\
\mathrm{kg} / \mathrm{ha}\end{array}$ & $\begin{array}{c}\text { Denitrification } \\
\mathrm{kg} / \mathrm{ha}\end{array}$ \\
\hline 336 & 341 & 134 & 148 & 234 & 0 \\
\hline
\end{tabular}


maximum allowable value for drinking water, and is a suitable tool for the assessment of uncertainty in local estimation. Based on the results, the standard error maps portrayed the suitable reliability of the prediction map, although extra sampling points are suggested for monitoring, especially near the boundaries to reduce the estimation error in a non-sampled region. It has also been shown that land use plays an important role on the water quality change, such as the potato corps we found high nitrate concentration. Therefore, integrated aquifer management strategies can be designed when water quality analyses are complimented with land use. The calibrated and validated PILOTEN model was applied to field experiments in a Mediterranean area (Morocco, Spain, French) where potato cropping systems under common local agricultural management practices were implemented. PILOTEN was able to predict water content at different depths and nitrate concentration in drained water past $0.9 \mathrm{~m}$ depth with reasonable accuracy providing good predictions compared to field observations. The model simulated the amount of water drained and $\mathrm{N}$ leached below the root zone. Also, the adopted approach of comparing total nitrogen input content in soil of High-Cheliff to the $\mathrm{N}$ leaching under potao crops (the main culture in the region) and simulated data at $0.9 \mathrm{~m}$ depth resulted in a good option for the modelling. This extra $N$ input to the system from irrigation water should be considered in the $N$ budget when designing fertilizer applications following crop requirements. Planned measures to reduce the impact of fertilizers and irrigation on the aquifer need to be taken by the agricultural and water sectors. However, these options should rely on technical and socio-economic requirements.

\section{REFERENCES}

[1] Alaa, A., Masoud., 2014. Simulation of nitrate leaching under potato crops in a Mediterranean area.Influence of frost prevention irrigation on nitrogen transport, Agricultural Water Management. 98 1629- 1640.

[2] ABH-CZ., 2004. Hydraulic Cadastre, Mission I. Basin Agency Cheliff-Zahrez, Algeria , p 80.

[3] Achour,F., 1997. Hydrological and water availability conditions in semiarid region: Application of new methodologies in the Cheliff Basin, Algeria. PhD thesis, University of Franche -Comté, France, 261 p.
[4] ANRH., 1993. Pollution by nitrates. National Agency of Water Resources, Algeria, $15 \mathrm{p}$

[5] ANRH., 2011. Hydrogeological Yearbook of alluvial aquifer of high and medium Cheliff. National Agency of Water Resources, Algeria, 13 p.

[6] Barton, L., McLay, C.D., Schipper, L.A., \& Smith, C.T., 1999. Annual denitrification rates in agricultural and forest soils: a review, Australian Journal of Soil Research, 37, 10731093..

[7] Bettahar, N., Ali Benamara, A., Kettab, A., \& Douaoui, A., 2000. Risk of nitrate pollution in semi-arid areas. If Valley Western Middle Cheliff. Rev. Sci. Water, 22 (1), 69-78, ISSN 0298-6663

[8] Bettahar, N., \& Douaoui, A., 2001. Spatial evolution of the hardness of the water in the plains of Cheliff. Using the geostatistical approach. Bull. Ass. Geogr . Feeder. Territ. , 9, 115-121.

[9]Bettahar, N., \& Douaoui, A., 2009. Effect of the pedoclimatic conditions are nitrogen assessment. Arab Water World - AWW, XXXI, 8, 41-42

[10] Bettahar, N., 2012. Effect of the Climate and Soil Characteristics on the Nitrogen Balance in the North of Algeria, Horticulture, Prof. Alejandro Isabel Luna Maldonado (Ed.), ISBN: 978-953-51-0252-6, InTech.

[11] Bierkens, M.E.P., \& Burrough, P.A., 1993. The indicator approach to categorical data.I.Theory. J. Soil Sci . , 44, 361-368

[12] Boulaine, J.L.G., 1957. Soil Survey Plains Cheliff. PhD thesis, University of Algiers, Algeria, $565 \mathrm{p}$.

[13] Chelloufi, H., \& Jacquin, F., 2000. Interactions water nitrates. Comparative study of nitrate leaching in four soil types. JEEC. , 290-296.

[14]CORPEN., (1988, 1999 and 2001). CORPEN standards for estimating nitrogen produced on the farm. PMPOA Circular No. 5010 of 15 May 2003.

[15] Daoud, Y., 1993.Contribution to the study of soil plains Chéliff. The phenomenon of salinisation, affect the physical properties of clay soils. Thesis Doct status, INA Algiers, $233 \mathrm{p}$.

[16] Derdour, H., 1981. Contribution to the study of the influence of exchangeable sodium on the behavior of the soil compaction. Magister thesis INA Algiers, 46p.

[17] Doltra, J., Mu noz, P., 2010. Simulation of nitrogen leaching from a fertigated crop rotation in a Mediterranean climate using the EU-Rotate $\mathrm{N}$ and hydrus2D mod-els. Agricultural Water Management 97 (2), 277-285.

[18] Douaoui, A., 2005. Spatial variability of salinity and its relation with some soil characteristics of the plain of Lower Cheliff. Contribution of geostatistics and remote sensing. Thesis Doct status, INA Algiers, $233 \mathrm{p}$.

[19] Douaoui, A., Herve, N., \& Walter, C.H., 2006. Detecting salinity hazards Within a semi- arid context by moyen de -combining soil and remote -sensing data. Geoderma , 134, 217-230.

[20] Firestone, M.K., 1982. Biological denitrification . In: Nitrogen in agricultural soils. 
[21] Garin P., S. Morardet, et J.C. Mailhol. 2000. Analyse de différents modes d'allocation des volumes de référence sur le fleuve Charente, à l'amont d'Angoulème. Rapport d'étude pour le compte du Conseil Général de la Charente, 40p

[22] Haddaj, D., 1970. Influence of cultivation methods on the structural degradation of soils irrigated perimeters of the High Chéliff These INA Algiers, 86p.

[23] Hayenes, R.J., 1986b. Uptake and assimilation of mineral nitrogen by plants. In: Mineral nitrogen in the plant soil system, physiological ecology. Kozlowsky, T.T. (Editor). Madison, Wisconsin, USA, pp. 303- 378.

[24] Henault, C., \& Albacore, J.C., 1995. Quantification of denitrification and emissions of nitrous oxide (N2O) from soils. Agronomy, 15, 321-355

[25] Jacques, F., Laurent, B ., Gabrielle, R ., Jean-C, M ., Pierre, R., Philippe, L G., 2013. A simulation tool adapted to the management of water resources planning in the context of a participatory approach, the economic model of irrigated agriculture, Focus, Water Science \& Territories No. 11-2013

[26] Kettab, A., 2005. Water for Sustainable Development (SD). An International Publication of Engineering Sciences. Algerian J. Technol., ISSN 1111 - 357x, Special Issue, 521-524.

[27] Khaledian, M.-R., Mailhol, J.-C., Ruelle, P., Rosique, P., 2009. Adapting PILOTE model for water and yield management under direct seeding system: the case of corn and durum wheat in a Mediterranean context, Agric. Water Manag., 96(5), p. 757-770.

[28] Machet, J. M., Stone, D., Appeal, S., \& Remy, J,C., (1987). Meaning the real duty cycle and consequently for nitrogen fertilization of cultures. CR Acad. Agric. France, 3, 3955.

[29] Mailhol ,J.C., Vidal, A., Labbé, S., 1992. Evaluation des consommations théoriques en eau d'irrigation. Télédétection et SIG pour la cartographie des besoins en eau des principales cultures sur le casier 1 de la BRL, Rapport d'étude pour le compte de la BRL 70p.

[30] Mailhol, J.-C., OLUFAYO, A., RUELLE, P., 1997, Sorghum and sunflower evapotranspiration and yield from simulated leaf area index, Agric. Water Manag., n 35, p. 167182

[31] Mailhol, J.C., 2001. Contribution à l'amélioration des pratiques d'irrigation à la raie par une modélisation simplifiée à l'échelle de la parcelle et de la saison. Thèse de Doctorat Univ. Montp. II, $260 \mathrm{p}+$ annexes.
[32] Martin, C., 2003. Mécanismes hydrologiques et hydrochimiques impliqués dans les variations saisonnières des teneurs en nitrate dans les bassins versants agricoles. Approche expérimentale et modélisation. Thèse Doctorat, Ecole de Renne 1- France, $269 \mathrm{p}$.

[33] Mattauer,M., 1958. Geological Survey of Eastern Ouarsenis (Algeria). Es thesis, University of Besançon, France, $343 \mathrm{p}$.

[34] Perronon, A., 1957. Geological Survey subtidal Neogene basins of the North West Algeria. PhD thesis, University of Algiers, Algeria, $115 \mathrm{p}$

[35] Rrmrnieras, G., 1980. Hydrology Engineering. EYROLLES (Editor), 2nd ed., Paris, France, 455 p.

[36]Rodier, G., 1996. Analysis of water, natural water, wastewater, seawater 8th edition, Dunod, Paris, France, 1365 p.

[37] SCET AGRI., 1984a. Hydrology - Hydrogeology and resource balance. Study of the redevelopment and extension of the scope of the average Chéliff. Rap A1.1.2. Pub. Ministry of Water Resources, Algeria, $72 \mathrm{p}$.

[38] SCET AGRI., 1984b. Assessment of soil resources. Study of the redevelopment and extension of the scope of the average Cheliff. Rap A1 .2.1. Pub. Ministry of Water Resources, Algeria, 35p

[39] Smith, M.S., \& Tiedge, J.M., 1979. Phases of denitrification Following oxygen depletion in soil. Soil Biol. Biochem. , 11, 261-267.

[40] Stevenson, F.J., Editor. Am Soc. Agron. , Madison, Wisconsin, USA, pp. 289-318.

[41] Tremblay, N., Scharpf, H. C., Weier, U., Laurence, H., \& Owen, J., 2001. Board of nitrogen in vegetable crops, Guide for rational fertilization. Agriculture and Agri-Food Canada, $70 \mathrm{p}$

[42] Xu, P., Hou, X., Zhou, F., Ying, N., \& Zhao, G., 2013. Estimation of nitrate leaching rate and loading deduced by agricultural fertilizers in the North China Plain. Journal of Environmental Quality Huanjing Kexue Xuebao/Acta Scientiae Circumstantiae Volume 33, Issue 11, Pages 3173-3180 